\title{
Holstein and Jersey Steers Differ in Rumen Microbiota and Enteric Methane Emissions Even Fed the Same Total Mixed Ration
}

\section{OPEN ACCESS}

Edited by:

Robert Czajkowski,

University of Gdańsk, Poland

Reviewed by:

Stefan Muetzel,

AgResearch Ltd., New Zealand

Metha Wanapat,

Khon Kaen University, Thailand

*Correspondence:

Sang-Suk Lee

rumen@sunchon.ac.kr;

rumen@scnu.ac.kr

Specialty section:

This article was submitted to

Microbial Symbioses,

a section of the journal

Frontiers in Microbiology

Received: 31 August 2020

Accepted: 15 February 2021

Published: 18 March 2021

Citation:

Islam M, Kim S-H, Ramos SC, Mamuad LL, Son A-R, Yu Z, Lee S-S, Cho Y-I and Lee S-S (2021) Holstein and Jersey Steers Differ in Rumen

Microbiota and Enteric Methane Emissions Even Fed the Same Total

Mixed Ration.

Front. Microbiol. 12:601061. doi: 10.3389/fmicb.2021.601061

\section{Mahfuzul Islam 1,2, Seon-Ho Kim ${ }^{1}$, Sonny C. Ramos ${ }^{1}$, Lovelia L. Mamuad ${ }^{1}$, A-Rang Son', Zhongtang Yu ${ }^{3}$, Sung-Sil Lee ${ }^{4}$, Yong-II Cho ${ }^{5}$ and Sang-Suk Lee ${ }^{\text {* }}$}

${ }^{1}$ Ruminant Nutrition and Anaerobe Laboratory, Department of Animal Science and Technology, Sunchon National University, Suncheon, South Korea, ${ }^{2}$ Department of Microbiology and Parasitology, Sher-e-Bangla Agricultural University, Dhaka, Bangladesh, ${ }^{3}$ Department of Animal Sciences, The Ohio State University, Columbus, OH, United States, ${ }^{4}$ Institute of Agriculture and Life Science and University-Centered Labs, Gyeongsang National University, Jinju, South Korea, ${ }^{5}$ Animal Disease and Diagnostic Laboratory, Department of Animal Science and Technology, Sunchon National University, Suncheon, South Korea

Previous studies have focused on the rumen microbiome and enteric methane $\left(\mathrm{CH}_{4}\right)$ emissions in dairy cows, yet little is known about steers, especially steers of dairy breeds. In the present study, we comparatively examined the rumen microbiota, fermentation characteristics, and $\mathrm{CH}_{4}$ emissions from six non-cannulated Holstein $(710.33 \pm 43.02 \mathrm{~kg})$ and six Jersey $(559.67 \pm 32.72 \mathrm{~kg})$ steers. The steers were fed the same total mixed ration (TMR) for 30 days. After 25 days of adaptation to the diet, $\mathrm{CH}_{4}$ emissions were measured using GreenFeed for three consecutive days, and rumen fluid samples were collected on last day using stomach tubing before feeding $(0 \mathrm{~h})$ and $6 \mathrm{~h}$ after feeding. $\mathrm{CH}_{4}$ production (g/d/animal), $\mathrm{CH}_{4}$ yield $(\mathrm{g} / \mathrm{kg} \mathrm{DMl})$, and $\mathrm{CH}_{4}$ intensity $\left(\mathrm{g} / \mathrm{kg} \mathrm{BW} \mathrm{BW}^{0.75}\right)$ were higher in the Jersey steers than in the Holstein steers. The lowest $\mathrm{pH}$ value was recorded at $6 \mathrm{~h}$ after feeding. The Jersey steers had lower rumen $\mathrm{pH}$ and a higher concentration of ammonia-nitrogen $\left(\mathrm{NH}_{3}-\mathrm{N}\right)$. The Jersey steers had a numerically higher molar proportion of acetate than the Holstein steers, but the opposite was true for that of propionate. Metataxonomic analysis of the rumen microbiota showed that the two breeds had similar species richness, Shannon, and inverse Simpson diversity indexes. Principal coordinates analysis showed that the overall rumen microbiota was different between the two breeds. Both breeds were dominated by Prevotella ruminicola, and its highest relative abundance was observed $6 \mathrm{~h}$ after feeding. The genera Ethanoligenens, Succinivibrio, and the species Ethanoligenens harbinense, Succinivibrio dextrinosolvens, Prevotella micans, Prevotella copri, Prevotella oris, Prevotella baroniae, and Treponema succinifaciens were more abundant in Holstein steers while the genera Capnocytophaga, Lachnoclostridium, Barnesiella, Oscillibacter, Galbibacter, and the species Capnocytophaga cynodegmi, Galbibacter mesophilus, Barnesiella intestinihominis, Prevotella shahii, and Oscillibacter ruminantium in the Jersey steers. The Jersey steers were dominated by Methanobrevibacter millerae while the Holstein steers by Methanobrevibacter olleyae. The overall results suggest that sampling 
hour has little influence on the rumen microbiota; however, breeds of steers can affect the assemblage of the rumen microbiota and different mitigation strategies may be needed to effectively manipulate the rumen microbiota and mitigate enteric $\mathrm{CH}_{4}$ emissions from these steers.

Keywords: enteric methane emissions, Holstein steer, Jersey steer, rumen fermentation, rumen microbiota

\section{INTRODUCTION}

Holstein and Jersey are two major dairy breeds for milk production. However, steers of these breeds also contribute to beef production. To meet the ever-increasing demand for milk and beef by the growing global population and rising living standards, improvement of animal performance is required. In the past decade, researchers have embraced next-generation sequencing (NGS) techniques to understand the underlying interactions among diets, the rumen microbiome, and adult ruminants to help improve productivity and reduce the output of wastes (e.g., $\mathrm{CH}_{4}$ and $\mathrm{NH}_{3}-\mathrm{N}$ ). Recently, O'Hara et al. (2020) reviewed the association of the rumen microbiota and fermentation products and the effects of such association on valuable traits such as feed efficiency and $\mathrm{CH}_{4}$ emissions. In the rumen of most ruminant species, Firmicutes, Bacteroidetes, and Proteobacteria are the dominant bacterial phyla, and Prevotella, Fibrobacter, and Butyrivibrio are the dominant bacterial genera, which can ferment a wide range of dietary polysaccharides and protein (O’Hara et al., 2020).

The rumen microbiome contributes either directly or indirectly to animal performance (Islam and Lee, 2018); however, the variation of feed efficiency has a significant association with differences in the rumen microbiome among individual ruminants (Li et al., 2019a; McLoughlin et al., 2020). Therefore, the rumen microbiome can be a potential target to manipulate not only to improve feed efficiency but also to reduce $\mathrm{CH}_{4}$ emissions. Enteric $\mathrm{CH}_{4}$ is produced primarily through hydrogenotrophic methanogenesis, the reduction of $\mathrm{CO}_{2}$ by $\mathrm{H}_{2}$ by methanogens (Moss et al., 2000; Ellis et al., 2008). $\mathrm{CH}_{4}$ is not only a potent greenhouse gas (GHG) but also represents a gross energy loss (Johnson and Johnson, 1995; Appuhamy et al., 2016). Earlier studies on $\mathrm{CH}_{4}$ emissions found inconsistent results between Holstein and Jersey dairy cows, with much less information available for steers of both breeds. Münger and Kreuzer $(2006,2008)$ reported that $\mathrm{CH}_{4}$ yield $(\mathrm{g} / \mathrm{kg}$ dry matter intake; DMI) was not different between Holstein and Jersey cows. In contrast, Olijhoek et al. (2018) reported a significantly higher $\mathrm{CH}_{4}$ yield in Jersey cows than in Holstein cows, either fed high-forage or high-concentrated diets or either allowed for a low or high feed refusal. Methanobrevibacter is the dominant genus of methanogens and the major $\mathrm{CH}_{4}$ producer in ruminants (Leahy et al., 2013; Henderson et al., 2015). King et al. (2011) reported that the Methanobrevibacter smithii, Methanobrevibacter gottschalkii, Methanobrevibacter millerae, and Methanobrevibacter thaueri (collectively known as SGMT) group of Methanobrevibacter were more abundant in Jersey cows than in Holstein cows, and it had a positive correlation with $\mathrm{CH}_{4}$ production. However, Cersosimo et al. (2016) reported similar communities of methanogens between Holstein and Jersey cows.

Diet plays a significant role in shaping the rumen microbiome, leading to differences in the rumen fermentation characteristics and $\mathrm{CH}_{4}$ emissions (Spor et al., 2011). Notably, types of diet such as high-forage vs. high-concentrate diets had a profound influence on the rumen microbiome, its fermentation characteristics, and enteric $\mathrm{CH}_{4}$ production (Zhang et al., 2017; Li et al., 2019b; Wang et al., 2020). Hence, to minimize the dietary influence on rumen microbiome when comparing different breeds, identical feed should be fed. As reported by Li et al. (2019a), host genetics has some influence on rumen microbiome and feed efficiency in several beef breeds, including Angus, Charolais, and Kinsella composite hybrid, but the effect on $\mathrm{CH}_{4}$ emissions remains undetermined. Another study showed that both rumen microbiome and host genetics could have a joint association with $\mathrm{CH}_{4}$ emissions in lactating Holstein cows (Difford et al., 2018), but no data on rumen fermentation parameters were reported. Several previous studies showed differences in rumen microbiome between Holstein and Jersey cows. For instance, Beecher et al. (2014) reported that the relative abundance of Ruminococcus flavefaciens was higher in Holstein cows than in Jersey cows, whereas no difference was observed in Fibrobacter succinogenes. Paz et al. (2016) reported that lactating Holstein and Jersey cows harbored a distinct rumen bacterial microbiota, with the former having a greater diversity and species richness than the latter. Prevotellaceae is the largest bacterial family in both Holstein and Jersey cows, but Lachnospiraceae and candidate family p-2534-18B5 were more abundant in Holstein cows than in Jersey cows (Paz et al., 2016). Despite the numerous previous studies on the rumen microbiome of Holstein and Jersey dairy cows, there is limited information on the rumen microbiome in growing steers, especially steers of dairy breeds. To bridge this knowledge gap, comparative studies are needed. We hypothesized that Holstein and Jersey steers might harbor different rumen microbiome, which might influence their rumen fermentation and enteric $\mathrm{CH}_{4}$ emissions. The objective of the present study was to test the above hypothesis by comparing the rumen microbiota, rumen fermentation characteristics, and methane emissions.

\section{MATERIALS AND METHODS}

\section{Animal, Experimental Design, and Diet}

The animal experiment was conducted at the Sunchon National University (SCNU) Animal Farm under normal environmental conditions with a temperature-humidity index of $65.67 \pm 2.22$. 
The laboratory analysis was performed at the Ruminant Nutrition and Anaerobe Laboratory, Department of Animal Science and Technology, SCNU, Jeonnam, South Korea.

Six Holstein $(710.33 \pm 43.02 \mathrm{~kg})$ and six Jersey $(559.67 \pm 32.72 \mathrm{~kg})$ steers, both non-cannulated, at the age of about 27 months were fed the same total mixed ration (TMR) for 30 days, with the first 25 days for diet adaptation and the remaining 5 days for determination of DMI (the whole 5 days), $\mathrm{CH}_{4}$ measurement (the first 3 days), and rumen fluid sample collection (the last day). All steers were kept in individual stalls with feeding and water facilities. The steers were offered the same TMR (Table 1) once a day at $0900 \mathrm{~h}$ at a rate of $5-10 \%$ of refusal. DMI was measured as the difference between feed offered and the feed refusal. The average body weight (BW) was calculated as (the initial $\mathrm{BW}+$ the final $\mathrm{BW}$ )/2, and average daily gain (ADG) was recorded for the last 10 days of the experimental period. The TMR was sampled twice (at days 7 and 28) during the feeding trial, and the dry matter content was determined using a hot-air oven at $65^{\circ} \mathrm{C}$ for $72 \mathrm{~h}$ (Bharanidharan et al., 2018). The chemical composition of the TMR was analyzed following the standard methods (Aoac, 2005). The content of neutral detergent fiber (NDF) and acid detergent fiber (ADF) was determined per the protocols described by Van Soest (1973) and Van Soest et al. (1991), respectively.

\section{Enteric $\mathrm{CH}_{4}$ Measurements}

Enteric $\mathrm{CH}_{4}$ emissions were measured using a GreenFeed unit (C-Lock Inc., Rapid City, SD, United States) as described by Hammond et al. (2015) and Hristov et al. (2015) with minor modifications. Briefly, $\mathrm{CH}_{4}$ emissions were measured for each steer at eight different time points (00:00, 03:00, 06:00, 09:00, $12: 00,15: 00,18: 00$, and 21:00) for three consecutive days during the measurement period. The GreenFeed unit was installed in one corner of a large pan. At each measurement time, all steers were transferred to that pan from their stalls one after another. Each steer was allowed for access to the GreenFeed unit for approximately $10 \mathrm{~min}$. Molasses-coated concentrated pellets were used to attract the animals to the GreenFeed unit and ensure a proper head-down position within the hood for the measuring duration. The amount of pellets ingested by each steer during the measuring duration was not included in the DMI calculation. The entry and exit times for each animal, standard gas calibration, and $\mathrm{CO}_{2}$ recovery data were recorded and sent to C-Lock Inc., which calculated the $\mathrm{CH}_{4}$ emissions. The calculated data were received via a web-based data management system, and $\mathrm{CH}_{4}$ emissions were expressed as $\mathrm{CH}_{4}$ production $(\mathrm{g} / \mathrm{d}), \mathrm{CH}_{4}$ yield $(\mathrm{g} / \mathrm{kg} \mathrm{DMI})$, and $\mathrm{CH}_{4}$ intensity $\left(\mathrm{g} / \mathrm{kg} \mathrm{BW}^{0.75}\right)$.

\section{Sample Collection and Processing}

Rumen fluid samples were collected from each of the steers at two different time points: before feeding $(0 \mathrm{~h})$ and $6 \mathrm{~h}$ after feeding using stomach tubing on the last day of the experiment. To minimize contamination from the saliva, the first $300 \mathrm{ml}$ of each rumen fluid sample was discarded. The $\mathrm{pH}$ was measured immediately after collection with a $\mathrm{pH}$ meter (Seven Compact ${ }^{\mathrm{TM}}$ $\mathrm{pH} /$ Ion meter S220, Mettler Toledo, Switzerland). The rumen fluid sample collected from each steer was divided into three
TABLE 1 | Ingredients and chemical composition of the TMR fed to the steers.

\begin{tabular}{|c|c|}
\hline Ingredients & Compositions (\% of DM) \\
\hline Corn grain & 36.80 \\
\hline Corn gluten feed & 17.89 \\
\hline Lupin & 12.49 \\
\hline Wheat bran & 11.61 \\
\hline Oat hay & 20.26 \\
\hline Limestone (1 mm size) & 0.68 \\
\hline Vitamin premix ${ }^{1}$ & 0.07 \\
\hline Mineral premix ${ }^{2}$ & 0.07 \\
\hline Salt & 0.14 \\
\hline Total & 100.00 \\
\hline \multicolumn{2}{|c|}{ Chemical composition (\% as DM basis) } \\
\hline DM (\% as fed basis) & 73.06 \\
\hline Crude protein & 19.86 \\
\hline Crude fiber & 9.23 \\
\hline Crude fat & 4.60 \\
\hline Ash & 7.56 \\
\hline Calcium & 0.74 \\
\hline Phosphorous & 0.40 \\
\hline NDF & 32.17 \\
\hline ADF & 14.29 \\
\hline
\end{tabular}

${ }^{1}$ The vitamin premix contained $(\mathrm{g} / \mathrm{kg}) \mathrm{L}$-ascorbic acid, 121.2; DL- $\alpha$-tocopherol acetate, 18.8; thiamin hydrochloride, 2.7; riboflavin, 9.1; pyridoxine hydrochloride, 1.8; niacin, 36.4; Ca-D-pantothenate, 12.7; myo-inositol, 181.8; D-biotin, 0.27; folic acid, 0.68; p-aminobenzoic acid, 18.2; menadione, 1.8; retinal acetate, 0.73; cholecalciferol, 0.003; and cyanocobalamin, 0.003; and the remaining was cellulose.

${ }^{2}$ The mineral premix contained $(\mathrm{g} / \mathrm{kg}) \mathrm{MgSO}_{4} \cdot 7 \mathrm{H}_{2} \mathrm{O}, 80.0 ; \mathrm{NaH}_{2} \mathrm{PO}_{4} \cdot 2 \mathrm{H}_{2} \mathrm{O}$, 370.0; KCl, 130.0; ferric citrate, 40.0; $\mathrm{ZnSO}_{4} \cdot 7 \mathrm{H}_{2} \mathrm{O}$, 20.0; Ca-lactate, 356.5; $\mathrm{CuCl}_{2}, 0.2 ; \mathrm{AlCl}_{3} \cdot 6 \mathrm{H}_{2} \mathrm{O}, 0.15 ; \mathrm{Kl}, 0.15 ; \mathrm{Na}_{2} \mathrm{Se}_{2} \mathrm{O}_{3}, 0.01 ; \mathrm{MnSO}_{4} \cdot \mathrm{H}_{2} \mathrm{O}, 2.0$; and $\mathrm{CoCl}_{2} \cdot 6 \mathrm{H}_{2} \mathrm{O}, 1.0$.

$D M$, dry matter; NDF, neutral detergent fiber; $A D F$, acid detergent fiber.

separate aliquots, which were transferred to the laboratory and stored at $-80^{\circ} \mathrm{C}$ until subsequent analysis for ammonia nitrogen $\left(\mathrm{NH}_{3}-\mathrm{N}\right)$, volatile fatty acid (VFA), and rumen microbiota.

\section{Analysis of $\mathrm{NH}_{3}-\mathrm{N}$ and VFA Concentrations}

The concentration of $\mathrm{NH}_{3}-\mathrm{N}$ was measured colorimetrically using a Libra S22 spectrophotometer (CB40FJ; Biochrom Ltd., Cambourne, United Kingdom) following the protocol described by Chaney and Marbach (1962). The VFA concentration was measured according to the methods described by Tabaru et al. (1988) and Han et al. (2005) using high-performance liquid chromatography (HPLC; Agilent Technologies 1200 series, Waldbronn, Baden-Wurttemberg, Germany). A UV detector (set at 210 and $220 \mathrm{~nm}$ ), a METACARB87H column (Varian, Palo Alto, CA, United States), and a buffered solvent $\left(0.0085 \mathrm{~N} \mathrm{H}_{2} \mathrm{SO}_{4}\right)$ at a flow rate of $0.6 \mathrm{~mL} / \mathrm{min}$ were used to run the HPLC.

\section{DNA Extraction and Metataxonomic Analysis}

The rumen fluid samples (two per each of the 12 steers, 24 in total) were sent to Macrogen Inc. (Seoul, South Korea) for 
DNA extraction and metataxonomic analysis of the rumen microbiota. Briefly, the DNA was extracted using a PowerSoil ${ }^{\circledR}$ DNA Isolation Kit (Cat. No. 12888, MO BIO) following the manufacturer's protocol (Claassen et al., 2013). The quality and quantity of DNA were checked using PicoGreen and Nanodrop. The Illumina 16S Metagenomic Sequencing Library protocols were followed to prepare the amplicon library of each sample, which uses two-step PCR amplification of the $\mathrm{V} 3-\mathrm{V} 4$ region of the $16 \mathrm{~S}$ rRNA genes using primers Bakt_341F (5'-AGATGTGTATAAGAGACAG-3') and Bakt_805R (5'GATGTGTATAAGAGACAGG-3') (Klindworth et al., 2013), with multiplexing indices and Illumina sequencing adapters being introduced in the second PCR (10 cycles). The individual amplicon libraries were normalized after quantification using PicoGreen, sizes-verified using the TapeStation DNA ScreenTape D1000 (Agilent), pooled at an equal molar ratio, and then sequenced on a MiSeq system (Illumina, San Diego, CA, United States) using the $2 \times 300 \mathrm{bp}$ kit. The raw sequence data were trimmed by Trimmomatic (v0.38) (Bolger et al., 2014), and the two reads were joined using the FLASH (1.2.11) program (Magoč and Salzberg, 2011). Sequences shorter than 400 bp were discarded. The rDnaTools was used to identify and remove chimeric sequences ${ }^{1}$. Samples were subsampled to an even depth of 10,000 sequences per sample to avoid bias generated due to different sequencing depths. The quality-filtered sequences were clustered into operational taxonomic units (OTU) at 97\% sequence similarity using CD-HIT-OTU ( $\mathrm{Li}$ et al., 2012). The representative sequence of each OTU was compared using BLASTN (v2.4.0) (Zhang et al., 2000) against the 16S Microbial DB of $\mathrm{NCBI}^{2}$ for taxonomic assignment. Alpha diversity measurements including the Shannon diversity index, Inverse Simpson diversity index, and Chaol richness estimate were determined using QIIME (v1.8). The overall rumen microbiota was compared using principal coordinates analysis (PCoA) based on unweighted UniFrac distance. In addition, the Bray-Curtis distance dissimilarity matrix was used to produce PCoA ellipse at 95\% confidence using $\mathrm{R}$ (v3.6.2 and package vegan 2.5-6) to assess the difference in overall rumen microbiota between the two breeds.

\section{Statistical Analysis}

All the data of growth performance and $\mathrm{CH}_{4}$ emissions were analyzed using the independent group $t$-test (PROC TTEST), and the data of rumen fermentation, alpha diversity measurements and relative abundance of individual taxa of the rumen microbiota were analyzed using the Mixed procedure in SAS (version 9.4; SAS Institute Inc., Cary, NC, United States) (SAS, 2013). The model included the fixed effects of breed, sampling hour, and the interaction between breeds and sampling hours, and the random effect included the steers nested within the breeds. Significant difference was declared when $P$-value was $<0.05$, while trend was declared at $0.05<P \leq 0.1$.

${ }^{1}$ https://github.com/PacificBiosciences/rDnaTools

${ }^{2}$ https://www.ncbi.nlm.nih.gov/refseq/targetedloci/16S_process/

\section{RESULTS}

\section{Growth Performance and Enteric $\mathbf{C H}_{4}$ Emissions}

The growth performance of and $\mathrm{CH}_{4}$ emissions from the Holstein and the Jersey steers were shown in Table 2. The Holstein steers had a significantly higher average BW and metabolic BW $\left(\mathrm{BW}^{0.75}\right)$ than the Jersey steers $(P<0.05)$. Similarly, the Holstein steers had a higher $(P<0.05)$ DMI $(\mathrm{kg} / \mathrm{d})$ and ADG $(\mathrm{kg} / \mathrm{d})$ than the Jersey steers (17.49 vs. 13.57 and 1.48 vs. 1.02, respectively). However, DMI (kg/100 kg BW) was similar in both breeds. The $\mathrm{CH}_{4}$ production $(\mathrm{g} / \mathrm{d}), \mathrm{CH}_{4}$ yield $(\mathrm{g} / \mathrm{kg} \mathrm{DMI})$, and $\mathrm{CH}_{4}$ intensity $\left(\mathrm{g} / \mathrm{kg} \mathrm{BW} \mathrm{BW}^{0.75}\right)$ were higher in the Jersey steers than in the Holstein steers (226.49 vs. $165.46,16.89$ vs. 9.69 , and 1.96 vs. 1.19 , respectively; $P$-value: $0.124,0.041$, and 0.054 , respectively).

\section{Rumen Fermentation Characteristics}

The rumen fermentation parameters of the Holstein and Jersey steers at the two sampling different time points were analyzed and the results are presented in Table 3. A lower rumen $\mathrm{pH}$ (by about $0.2 \mathrm{pH}$ unit) was recorded in the Jersey steers than in the Holstein steers at both sampling hours $(P=0.013)$, and the $\mathrm{pH}$ tended to be lower at $6 \mathrm{~h}$ than at $0 \mathrm{~h}$ in both breeds $(P=0.071)$. The $\mathrm{NH}_{3}-\mathrm{N}$ concentration $(\mathrm{mg} / \mathrm{dl})$ was significantly higher $(P<0.05)$ in the Jersey steers $(5.14$ and 5.72 at $0 \mathrm{~h}$ and $6 \mathrm{~h}$, respectively) than in the Holstein steers (2.98 and 2.94 at $0 \mathrm{~h}$ and $6 \mathrm{~h}$, respectively), but it was not affected by sampling hour $(P>0.05)$. The total VFA concentration and the molar proportion of acetate were numerically higher in the Jersey steers, while the molar proportion of propionate was numerically higher in the Holstein steers $(P>0.05)$. The butyrate concentration was significantly increased over time after feeding in both breeds $(P<0.05)$, while acetate and propionate concentrations were numerically increased over time in both breeds $(P>0.05)$.

\section{Species Richness, Diversity, and Composition of Rumen Microbiota}

A total of 456,397 quality-filtered sequences resulted from processing more than 3 million raw reads produced from

TABLE 2 | Dry matter intake, average daily gain, and methane emissions of Holstein and Jersey steers.

\begin{tabular}{|c|c|c|c|c|}
\hline Parameters & Holstein & Jersey & SEM & $P$-value \\
\hline Average BW (kg) & 743.72 & 582.53 & 15.506 & $<0.001$ \\
\hline Average BW0.75 $(\mathrm{kg})$ & 142.37 & 118.55 & 2.276 & $<0.001$ \\
\hline $\mathrm{DMl}(\mathrm{kg} / \mathrm{d})$ & 17.49 & 13.57 & 0.221 & $<0.001$ \\
\hline DMI (kg/100 kg BW) & 2.35 & 2.33 & 0.026 & 0.533 \\
\hline $\mathrm{DMl}\left(\mathrm{g} / \mathrm{kg} \mathrm{BW}{ }^{0.75}\right)$ & 122.86 & 114.47 & 0.708 & $<0.001$ \\
\hline $\mathrm{ADG}(\mathrm{kg})$ & 1.48 & 1.02 & 0.078 & 0.021 \\
\hline $\mathrm{CH}_{4}$ production $(\mathrm{g} / \mathrm{d})$ & 165.46 & 226.49 & 22.222 & 0.124 \\
\hline $\mathrm{CH}_{4}$ yield (g/kg DMl) & 9.69 & 16.89 & 1.691 & 0.041 \\
\hline $\mathrm{CH}_{4}$ intensity $\left(\mathrm{g} / \mathrm{kg} \mathrm{BW}^{0.75}\right)$ & 1.19 & 1.96 & 0.197 & 0.054 \\
\hline
\end{tabular}


TABLE 3 | Rumen fermentation characteristics of Holstein and Jersey steers.

\begin{tabular}{|c|c|c|c|c|c|c|c|c|}
\hline \multirow[t]{2}{*}{ Parameters } & \multicolumn{2}{|c|}{ Holstein } & \multicolumn{2}{|c|}{ Jersey } & \multirow[t]{2}{*}{ SEM } & \multicolumn{3}{|c|}{$P$-value } \\
\hline & $\mathbf{O h}$ & $6 \mathrm{~h}$ & $\mathbf{O h}$ & $6 \mathrm{~h}$ & & Breed & Hour & $B \times H$ \\
\hline $\mathrm{pH}$ & 6.84 & 6.70 & 6.63 & 6.46 & 0.080 & 0.013 & 0.071 & 0.896 \\
\hline $\mathrm{NH}_{3}-\mathrm{N}(\mathrm{mg} / \mathrm{dl})$ & 2.98 & 2.94 & 5.14 & 5.72 & 0.645 & 0.002 & 0.698 & 0.658 \\
\hline Total VFA (mM) & 68.46 & 74.89 & 66.08 & 77.01 & 5.028 & 0.980 & 0.110 & 0.660 \\
\hline Acetate (mM) & 43.40 & 46.47 & 41.79 & 48.61 & 3.683 & 0.945 & 0.218 & 0.630 \\
\hline Propionate (mM) & 13.08 & 15.12 & 12.09 & 14.50 & 1.317 & 0.636 & 0.206 & 0.914 \\
\hline Butyrate (mM) & 11.99 & 13.30 & 12.20 & 13.90 & 0.302 & 0.196 & 0.001 & 0.527 \\
\hline Acetate (\%) & 62.80 & 62.13 & 62.99 & 63.20 & 1.597 & 0.713 & 0.895 & 0.797 \\
\hline Propionate (\%) & 19.34 & 19.99 & 18.40 & 18.68 & 1.300 & 0.464 & 0.760 & 0.900 \\
\hline Butyrate (\%) & 17.86 & 17.87 & 18.61 & 18.13 & 0.977 & 0.633 & 0.822 & 0.812 \\
\hline A: $P$ ratio & 3.28 & 3.18 & 3.46 & 3.44 & 0.301 & 0.486 & 0.841 & 0.909 \\
\hline
\end{tabular}

$\mathrm{NH}_{3}-\mathrm{N}$, ammonia-nitrogen; VFA, volatile fatty acids; A: P, acetate: propionate ratio; SEM, standard error of the mean.

TABLE 4 | Sequence reads and alpha diversity measurements of rumen microbiota of Holstein and Jersey steers.

\begin{tabular}{|c|c|c|c|c|c|c|c|c|}
\hline \multirow[t]{2}{*}{ Parameters } & \multicolumn{2}{|c|}{ Holstein } & \multicolumn{2}{|c|}{ Jersey } & \multirow[t]{2}{*}{ SEM } & \multicolumn{3}{|c|}{$P$-value } \\
\hline & $\mathbf{O h}$ & $6 \mathrm{~h}$ & $\mathbf{O h}$ & $6 \mathrm{~h}$ & & Breed & Hour & $\mathbf{B} \times \mathbf{H}$ \\
\hline Sequence reads & 19,953 & 20,308 & 18,980 & 16,825 & 1507 & 0.179 & 0.580 & 0.442 \\
\hline OTUs observed & 752.67 & 733.17 & 736.67 & 692.17 & 20.07 & 0.186 & 0.140 & 0.555 \\
\hline Chao 1 estimate & 866.75 & 846.39 & 858.96 & 833.67 & 21.24 & 0.653 & 0.322 & 0.914 \\
\hline Shannon diversity index & 7.36 & 7.31 & 7.41 & 7.35 & 0.091 & 0.635 & 0.537 & 0.936 \\
\hline Inverse Simpson diversity index & 0.98 & 0.98 & 0.99 & 0.99 & 0.002 & 0.257 & 0.701 & 0.701 \\
\hline Goods coverage (\%) & 99.3 & 99.3 & 99.2 & 99.0 & 0.100 & 0.067 & 0.344 & 0.271 \\
\hline
\end{tabular}

OTUs, operational taxonomic units; SEM, standard error of the mean.

sequencing the 24 rumen fluid samples. On average more than 16,800 sequences were obtained for each sample, and the Good's coverage reached at least 99\% (Table 4). The two breeds had a similar number of observed OTUs, Chao 1 richness estimate, Shannon, and Simpson diversity indexes $(P>0.05)$. At the domain level, bacteria (99.78-99.86\%) were dominant among the rumen microbiota followed by archaea $(0.14-0.22 \%)$. The two breeds did not differ in the relative abundance of either domain irrespective of sampling hour $(P>0.05)$ (Supplementary Table 1). Among the archaea, Methanobrevibacter of the phylum Euryarchaeota was the most predominant genus in both breeds and at both sampling hours $(P>0.05)$ (Figure 1 and Supplementary Table 1). $M$. millerae and $M$. olleyae were the dominant species among the methanogens in both breeds and at both sampling hours; however, $M$. millerae was numerically more predominant in the Jersey steers while $M$. olleyae was more predominant in the Holstein steers $(P>0.05)$ (Figure 1 and Supplementary Table 1).

Bacteroidetes (61.98-64.84\%) followed by Firmicutes (32.17$34.76 \%$ ) were the largest bacterial phyla in both breeds and at both sampling hours, together representing $>95 \%$ of all bacteria, and these two phyla did not differ $(P>0.05)$ between the two breeds (Figure 2 and Supplementary Table 1). Tenericutes and Proteobacteria were the next two predominant phyla each with a relative abundance $>0.1 \%$, which were also not influenced by breed $(P>0.05)$. The relative abundance of Tenericutes, however, was lower at $6 \mathrm{~h}$ than at $0 \mathrm{~h}$ after feeding $(P<0.05)$. Fibrobacteres and Candidatus Melainabacteria were the least abundant phyla, and they differed significantly $(P<0.05)$ between the two breeds, with Fibrobacteres being more abundant in the Holstein steers, while Candidatus Melainabacteria being more abundant in the Jersey steers.

Thirty-two of the 212 identified bacterial genera had a relative abundance $\geq 0.1 \%$ at least in one breed and at one of the two sampling hours (Figure 3 and Supplementary Table 2). Prevotella was the most abundant bacterial genus regardless of breed or sampling hour, and it tended $(P=0.068)$ to be more predominant in the Holstein steers (35.19 and $42.11 \%$, at 0 and $6 \mathrm{~h}$, respectively) than in the Jersey steers (32.79 and $34.17 \%)$. The relative abundance of the genera Ethanoligenens, Succinivibrio, and Muribaculum was significantly higher in the Holstein steers, whereas Capnocytophaga, Galbibacter, Lachnoclostridium, Barnesiella, and Oscillibacter were more predominant in the Jersey steers $(P<0.05)$. Paludibacter, Ruminococcus, Paraprevotella, Intestinimonas, Succiniclasticum, Flintibacter, Bacteroides, and Christensenella were the other abundant bacterial genera (each with a relative abundance $>1 \%$ ) in both breeds and at both sampling hours, although there were no significant differences between the two breeds $(P>0.05)$. Sampling time did not influence genus-level relative abundance $(P>0.05)$ except for that of Paludibacter, Bacteroides, 


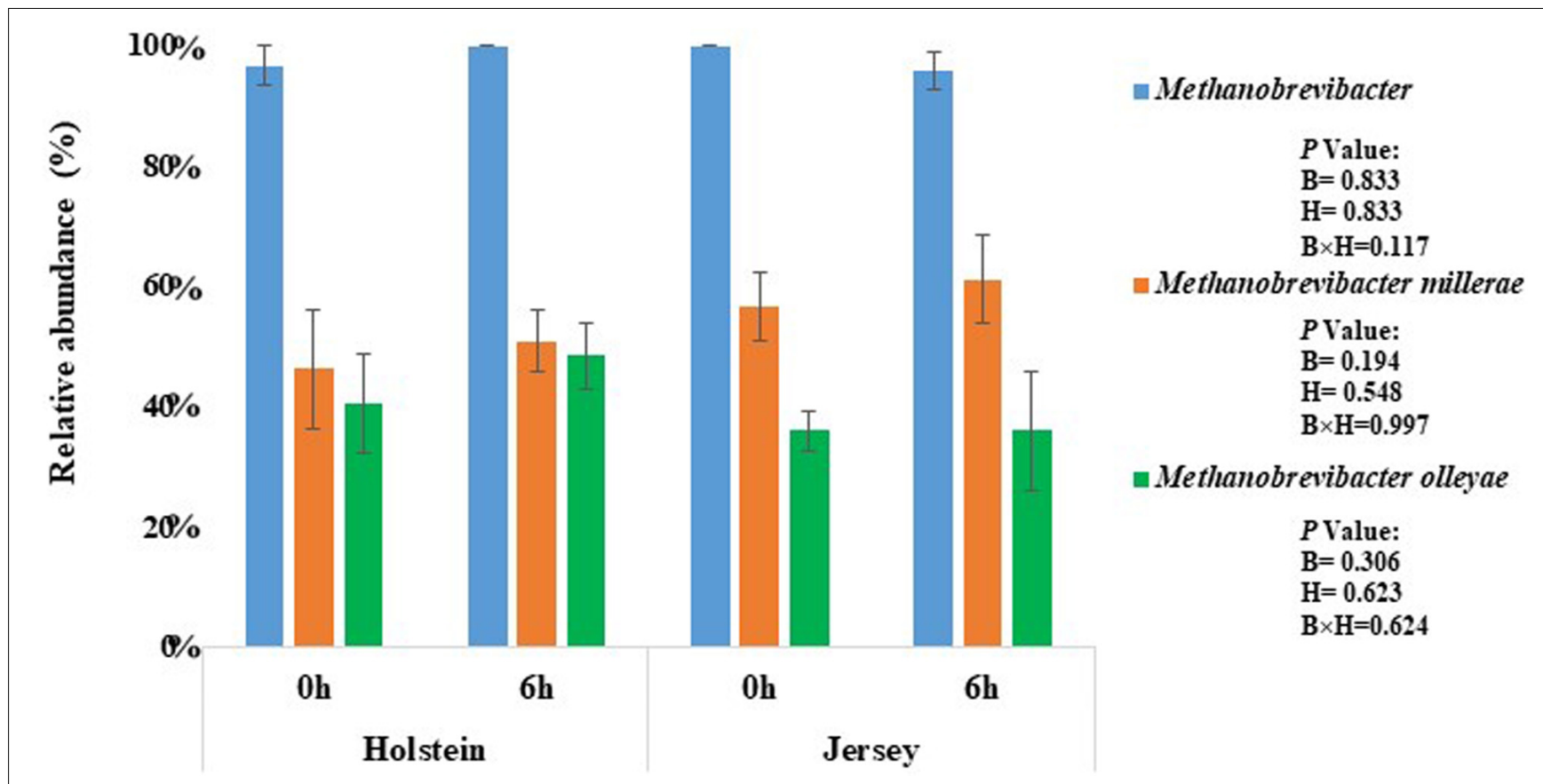

FIGURE 1 | Methanogens identified in the rumen of the Holstein and the Jersey Steers. Blue bars, Methanobrevibacter; orange bars. M. millerae; and green bars, M. olleyae.

Anaeroplasma, and Oscillibacter, which had a higher relative abundance at $0 \mathrm{~h}$ than at $6 \mathrm{~h}(P<0.05)$.

In total, 377 species or species-level OTUs of bacteria were identified across all the rumen samples, and 20 of them each had a relative abundance $\geq 1 \%$ at least in one breed and at one sampling hour (Table 5). Also, 7 species each had a relative abundance $\geq 0.5 \%$ at least in one breed and at one sampling hour, and they showed significant differences between the two breeds (Table 5). Pr. ruminicola was the most abundant bacterial species, and it was not affected by breeds $(P>0.05)$, but it tended to be more predominant at $6 \mathrm{~h}$ than at $0 \mathrm{~h}(P=0.069)$. Similarly, Paludibacter propionicigenes, Paraprevotella clara, Ruminococcus bromii, Prevotella brevis, Intestinimonas butyriciproducens, Succiniclasticum ruminis, Flintibacter butyricus, Bacteroides clarus, Prevotella oralis, and Christensenella massiliensis (each has relative abundance $\geq 1 \%$ ) did not differ between the two breeds $(P>0.05)$. Ethanoligenens harbinense, Prevotella micans, Prevotella copri, Prevotella oris, Millionella massiliensis, Succinivibrio dextrinosolvens, Prevotella baroniae, Acetivibrio alkalicellulosi, and Treponema succinifaciens were significantly more abundant in the Holstein steers, whereas Capnocytophaga cynodegmi, Galbibacter mesophilus, Barnesiella intestinihominis, Clostridium asparagiforme, Prevotella shahii, O. ruminantium, Erysipelothrix larvae, were significantly more abundant in the Jersey steers $(P<0.05)$. Based on PCoA and PCoA ellipse, the overall rumen microbiota was different between the Holstein and the Jersey steers (Figures 4, 5) even fed with the same TMR; however, no separation of overall rumen microbiome by sampling hour was noted on the PCoA plot (Figure 4).

\section{DISCUSSION}

The findings of the present study showed that the Holstein steers had a greater DMI (by $3.92 \mathrm{~kg}$ ) and ADG (by $0.46 \mathrm{~kg} / \mathrm{d}$ ) than Jersey steers when fed the same TMR diet. This is consistent with the heavier $\mathrm{BW}$ and $\mathrm{BW}^{0.75}$ of the Holstein steers than the Jersey steers and the report by Flay et al. (2019). The higher DMI by Holstein compared to the Jersey lactating and dry cows was also observed in previous studies (Prendiville et al., 2011; Beecher et al., 2014). However, Prendiville et al. (2011) also reported similar intake capacity (kg DM/100 kg BW) between these two breeds during dry period (1.95 vs. 2.04 in Holstein and Jersey, respectively). Likewise, our study observed nonsignificant differences of DMI (kg/100 kg BW) between breeds ( 2.35 vs. 2.33 in Holstein and Jersey, respectively). This finding as well as the same aged steer, used for feeding trial, minimizes the dietary influence of this study. Ruminal $\mathrm{pH}$ decreases with the increase of VFAs production by microbial fermentation or subsequently less absorption via the ruminal epithelium, and the less amount of saliva, which acts as a buffering agent, entered the rumen (Aikman et al., 2011). In the present study, the decreasing trend of $\mathrm{pH}$ over the sampling time might be due to the numerically increased production of VFAs over time. However, the significantly lower rumen $\mathrm{pH}$ observed in the Jersey steers compared to the Holstein steers might be due to the variation in the ruminal absorption and/or production of saliva between the two breeds. On the other hand, according to the Henderson-Hasselbalch equilibrium of $\mathrm{pH},\left[\mathrm{pH}=\mathrm{p} K_{a}+\log \right.$ $\left\{\left(\right.\right.$ Acid $\left.^{-}\right) /($HAcid $\left.)\right\}$; where $\mathrm{p} K_{a}$ is the negative log of the acid constant $K_{a}$ ], $\mathrm{pH}$ reduction potential of acetic acid ( $\left.\mathrm{p} K_{a} 4.76\right)$ 


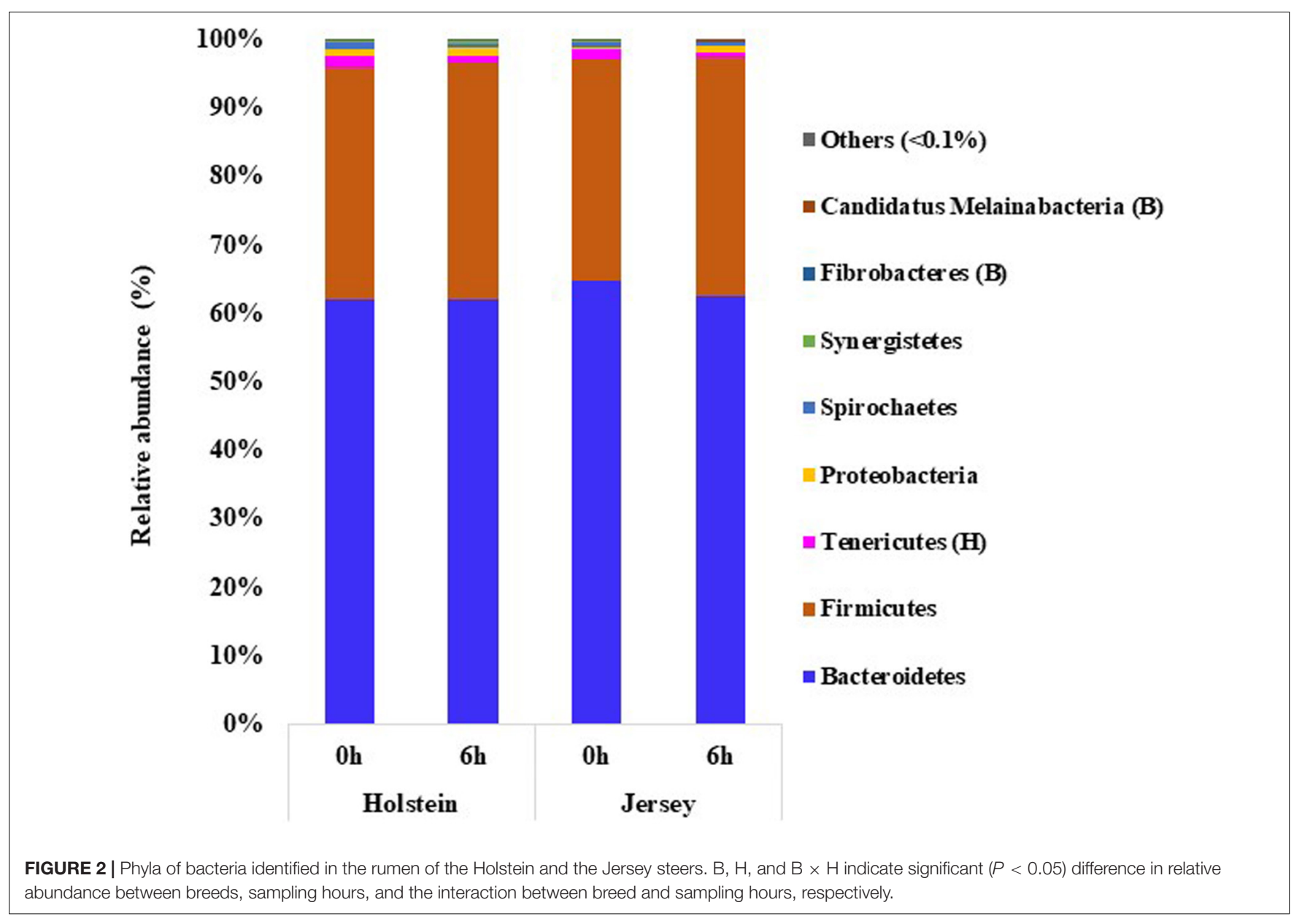

is comparatively higher followed by butyric acid $\left(\mathrm{p} K_{a} 4.82\right)$ and propionic acid ( $\mathrm{p} K_{a}$ 4.87) (Dijkstra et al., 2012). Therefore, the significantly lower $\mathrm{pH}$ in the Jersey steer further explained with the higher proportion of acetate and butyrate compared to the Holstein steers which had higher propionate proportion in this study. Rumen $\mathrm{NH}_{3}-\mathrm{N}$ concentration can be influenced by dietary protein breakdown, $\mathrm{NH}_{3}$ utilization by microbes, absorption by rumen wall, and urea hydrolysis in the rumen. The higher rumen $\mathrm{NH}_{3}-\mathrm{N}$ concentration noted in the Jersey steers probably indicates higher breakdown of dietary protein and/or less utilization by the rumen microbes or less ruminal absorption in the Jersey steers. The production of VFA is proportional to DMI, whereas the VFA concentrations in the rumen depend on the differences between the amount of production and the rate of absorption by the ruminal epithelium (Dieho et al., 2016). An earlier study reported that the Holstein dairy cows had a significantly higher molar proportion of propionate and lower proportion of acetate than the Jersey dairy cows (Olijhoek et al., 2018). They further stated that A:P ratio was higher in high $\mathrm{CH}_{4}$ emitting Jersey dairy cows compared to its counterpart Holstein dairy cows. However, in this study we only observed numerically higher proportion of propionate and lower proportion of acetate, and A:P ratio in the Holstein steers compared to the Jersey steers. The differences between the level of significance between these two studies may be due to the variation in the level of DMI and/or the production and absorption of individual VFAs by different breeds.

We hypothesized that Holstein steers would produce more $\mathrm{CH}_{4}$ (g/d) owing to their higher DMI, whereas Jersey steers would yield less $\mathrm{CH}_{4}$ (g/kg DMI) considering their greater feed efficiency (Spaans et al., 2018). However, our results showed numerically higher $\mathrm{CH}_{4}$ production (g/d), significantly higher $\mathrm{CH}_{4}$ yield $(\mathrm{g} / \mathrm{kg} \mathrm{DMI})$, and a trend of higher $\mathrm{CH}_{4}$ intensity $\left(\mathrm{g} / \mathrm{kg} \mathrm{BW} \mathrm{B}^{0.75}\right)$ in the Jersey steers than in the Holstein steers. This finding is in agreement with the results of Olijhoek et al. (2018) who reported that $\mathrm{CH}_{4}$ yield (g/kg DMI) was significantly higher in Jersey cows than in Holstein cows when fed high forage or high concentrate diets. Beside these, the recorded $\mathrm{CH}_{4}$ yield of Holstein steers in the present study was lower compared to some other studies; however, van Lingen et al. (2019) summarized the intercontinental databased to predict methane production (g/d) and yield (g/Kg DMI) by beef cattle where they presented that the range of methane production and yield with a high concentrate diets varies from 45 to $310 \mathrm{~g} / \mathrm{d}$, and 7.5 to $30.9 \mathrm{~g} / \mathrm{Kg} \mathrm{DMI}$, respectively. Bharanidharan et al. (2018) reported that the methane yield of Holstein steers ranged from 10.3 to $11.3 \mathrm{~g} / \mathrm{kg}$ DMI with a high concentrate TMR diet in Korea which was closer to our study. The $\mathrm{pH}$ of the 


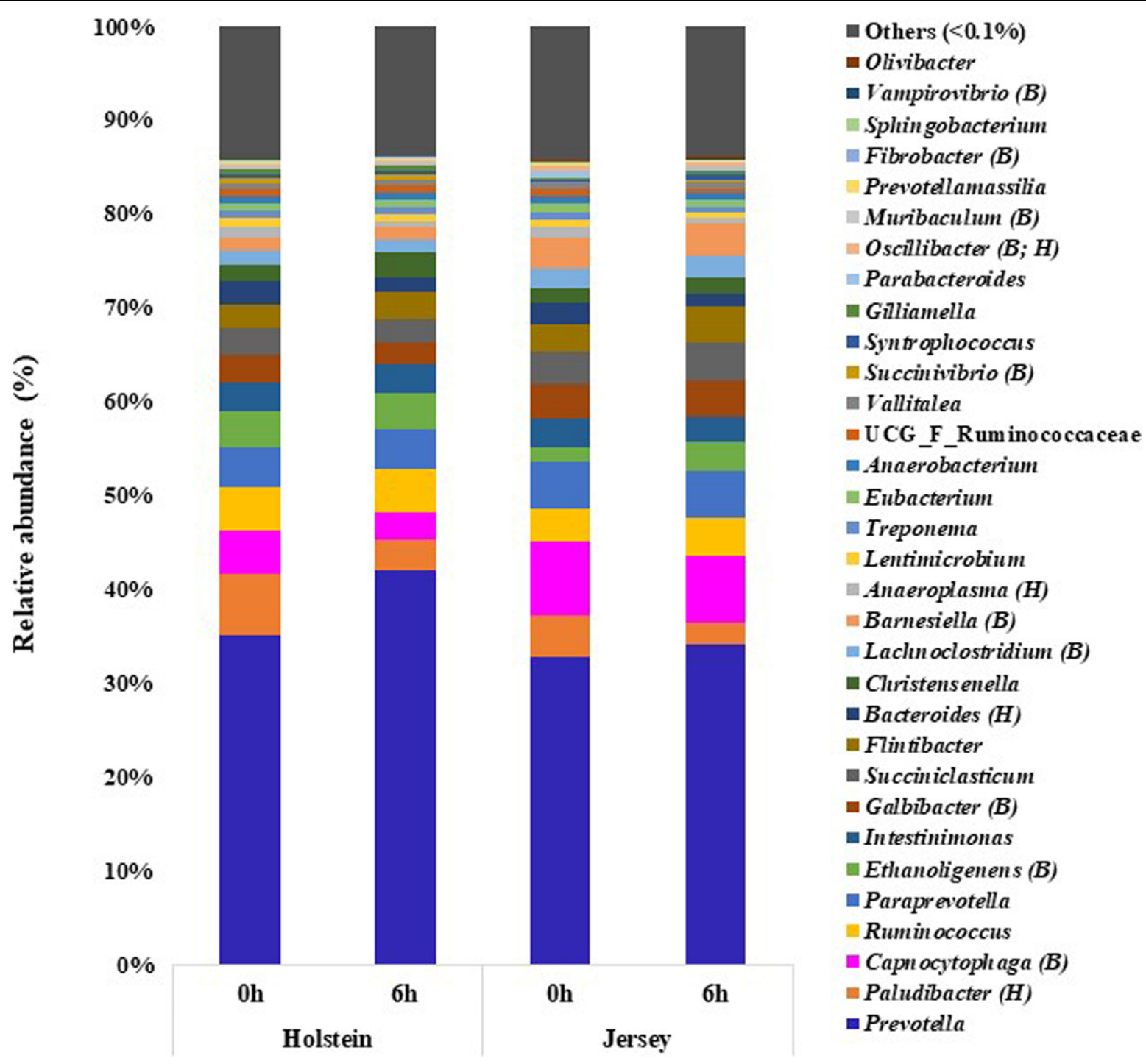

FIGURE 3 | Major genera (each having relative abundance $\geq 0.1 \%$ ) of bacteria identified in the rumen of the Holstein and the Jersey steers. $\mathrm{B}$ and $\mathrm{H}$ indicate significant $(P<0.05)$ differences in relative abundance between breeds and sampling hours, respectively.

above-mentioned study was varied from 6.3 to 6.7 which was also supported our study ( $\mathrm{pH}$ ranges from 6.46 to 6.84 ). In addition, the methane yield varies remarkably between high and low methane emitting cattle. Danielsson et al. (2017) reported that yield of $\mathrm{CH}_{4}$ varies between low and high methane emiting cows (12.4 vs. 14.5) without affecting acetate and propionate proportion. Wallace et al. (2015) also reported that the $\mathrm{CH}_{4}$ yield varied between low and high emitting Aberdeen Angus (7.63 vs. 18.14) and Limousin cross (9.29 vs. 20.13) beef cattle with a high concentrate diet. Methanobrevibacter represents the most predominant methanogens and is responsible for most of the methanogenesis in ruminants (Leahy et al., 2013; Henderson et al., 2015). It had a positive association with higher $\mathrm{CH}_{4}$ emissions in cattle (Wallace et al., 2014, 2015). King et al. (2011) reported that M. smithii, M. gottschalkii, M. millerae, and $M$. thaueri of Methanobrevibacter (collectively referred to as the SGMT group) were more dominant in the Jersey breed while $M$. ruminantium and $M$. olleyae (collectively referred to as the RO group) were more abundant in the Holstein breed. The higher $\mathrm{CH}_{4}$ production and $\mathrm{CH}_{4}$ yield in the Jersey steers might be associated with the numerically higher relative abundance of M. millerae in the Jersey steers compared to the Holstein steers, which had a higher relative abundance of $M$. olleyae. Methane production also correlates with the VFAs production. The major methanogenesis substrates, formate and $\mathrm{H}_{2}$, are produced during acetate production, while propionate production competes with methanogens for $\mathrm{H}_{2}$ (Baldwin et al., 1963; Moss et al., 2000; Kittelmann et al., 2014; Islam and Lee, 2019). An earlier study also reported that the A:P ratio was proportional to the enteric $\mathrm{CH}_{4}$ production (Olijhoek et al., 2018). Although not-significant; however, numerically higher acetate proportion, and $\mathrm{A}: \mathrm{P}$ ratio further correlate with the higher $\mathrm{CH}_{4}$ production in Jersey steer 


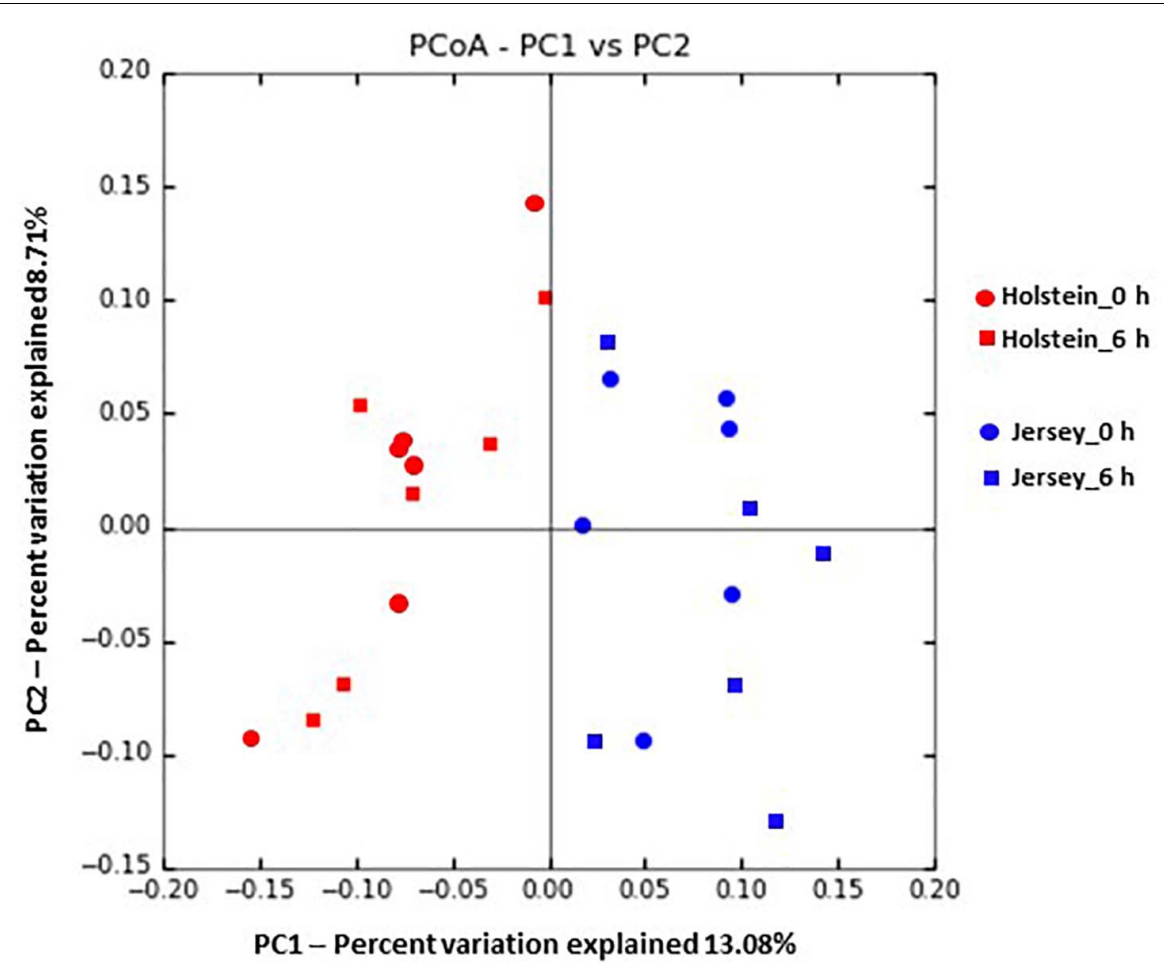

FIGURE 4 | Principal coordinates analysis plot based on unweighted-Unifrac distance showing the comparison of the overall rumen microbiota of the Holstein and the Jersey steers.

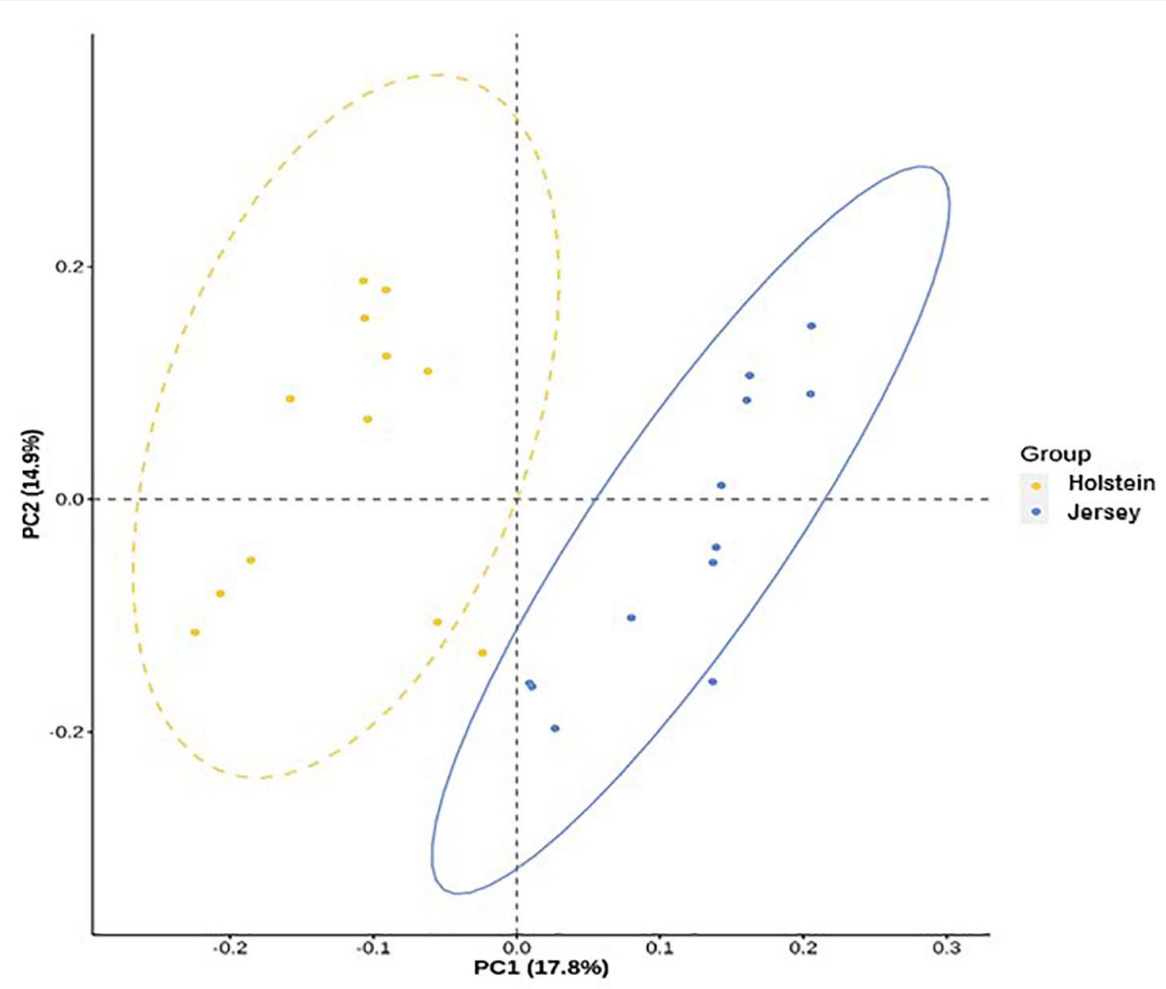

FIGURE 5 | Principal coordinates analysis plot based on Bray-Curtis dissimilarity with ellipse at 95\% confidence showing the comparison of the overall rumen microbiota of the Holstein and the Jersey steers. 
TABLE 5 | Major species of bacteria (each having relative abundance $\geq 1 \%$ ) and the species that both had relative abundance $\geq 0.5 \%$ at least in one breed and at one sampling hour and differed between the two breeds.

\begin{tabular}{|c|c|c|c|c|c|c|c|c|c|}
\hline \multirow[t]{2}{*}{ Phylum } & \multirow[t]{2}{*}{ Species } & \multicolumn{2}{|c|}{ Holstein } & \multicolumn{2}{|c|}{ Jersey } & \multirow[t]{2}{*}{ SEM } & \multicolumn{3}{|c|}{$P$-value } \\
\hline & & $\mathbf{O h}$ & $6 \mathrm{~h}$ & $\mathbf{O h}$ & $6 \mathrm{~h}$ & & Breed & Hour & $\mathbf{B} \times \mathbf{H}$ \\
\hline \multirow[t]{15}{*}{ Bacteroidetes } & Prevotella ruminicola & 22.61 & 29.19 & 22.52 & 24.49 & 2.153 & 0.292 & 0.069 & 0.312 \\
\hline & Paludibacter propionicigenes & 6.40 & 3.11 & 4.41 & 2.36 & 0.922 & 0.201 & 0.018 & 0.553 \\
\hline & Paraprevotella clara & 4.22 & 4.18 & 4.96 & 5.00 & 1.361 & 0.609 & 0.999 & 0.980 \\
\hline & Capnocytophaga cynodegmi & 3.90 & 2.48 & 7.13 & 6.52 & 0.708 & $<0.001$ & 0.198 & 0.596 \\
\hline & Prevotella brevis & 3.01 & 3.13 & 2.42 & 1.92 & 0.491 & 0.114 & 0.738 & 0.571 \\
\hline & Galbibacter mesophilus & 2.95 & 2.30 & 3.65 & 3.69 & 0.406 & 0.024 & 0.485 & 0.433 \\
\hline & Prevotella micans & 1.53 & 1.36 & 0.71 & 0.63 & 0.247 & 0.010 & 0.659 & 0.859 \\
\hline & Bacteroides clarus & 1.51 & 0.75 & 1.15 & 0.41 & 0.357 & 0.410 & $\underline{0.085}$ & 0.979 \\
\hline & Prevotella oralis & 1.43 & 1.79 & 1.98 & 2.40 & 0.449 & 0.237 & 0.417 & 0.946 \\
\hline & Barnesiella intestinihominis & 1.33 & 1.40 & 3.00 & 3.39 & 0.385 & $<0.001$ & 0.574 & 0.698 \\
\hline & Prevotella copri & 1.14 & 0.94 & 0.61 & 0.54 & 0.186 & 0.036 & 0.542 & 0.757 \\
\hline & Prevotella oris & 0.77 & 1.00 & 0.41 & 0.55 & 0.130 & 0.014 & 0.224 & 0.769 \\
\hline & Prevotella shahii & 0.52 & 0.40 & 0.79 & 1.00 & 0.119 & 0.003 & 0.719 & 0.201 \\
\hline & Millionella massiliensis & 0.72 & 0.72 & 0.49 & 0.49 & 0.107 & 0.043 & 0.976 & 1.000 \\
\hline & Prevotella baroniae & 0.57 & 0.87 & 0.13 & 0.09 & 0.153 & 0.004 & 0.488 & 0.358 \\
\hline \multirow[t]{10}{*}{ Firmicutes } & Ethanoligenens harbinense & 4.01 & 3.99 & 1.68 & 3.03 & 0.529 & 0.010 & 0.264 & 0.249 \\
\hline & Ruminococcus bromii & 3.35 & 3.65 & 2.24 & 3.12 & 0.468 & 0.126 & 0.264 & 0.576 \\
\hline & Intestinimonas butyriciproducens & 3.00 & 2.99 & 2.95 & 2.77 & 0.528 & 0.798 & 0.859 & 0.873 \\
\hline & Succiniclasticum ruminis & 2.78 & 2.53 & 3.48 & 4.04 & 0.719 & 0.152 & 0.838 & 0.585 \\
\hline & Flintibacter butyricus & 2.56 & 2.93 & 2.95 & 3.87 & 0.382 & 0.104 & 0.115 & 0.493 \\
\hline & Christensenella massiliensis & 1.33 & 2.11 & 1.18 & 1.33 & 0.330 & 0.192 & 0.193 & 0.374 \\
\hline & Clostridium asparagiforme & 1.22 & 0.97 & 1.83 & 1.87 & 0.244 & 0.006 & 0.682 & 0.557 \\
\hline & Acetivibrio alkalicellulosi & 0.55 & 0.40 & 0.22 & 0.18 & 0.091 & 0.018 & 0.396 & 0.585 \\
\hline & Oscillibacter ruminantium & 0.25 & 0.18 & 0.64 & 0.50 & 0.042 & $<0.001$ & 0.032 & 0.472 \\
\hline & Erysipelothrix larvae & 0.17 & 0.16 & 0.50 & 0.33 & 0.083 & 0.033 & 0.411 & 0.464 \\
\hline Proteobacteria & Succinivibrio dextrinosolvens & 0.58 & 0.53 & 0.05 & 0.25 & 0.149 & 0.039 & 0.680 & 0.502 \\
\hline Spirochaetes & Treponema succinifaciens & 0.54 & 0.41 & 0.14 & 0.11 & 0.081 & 0.003 & 0.458 & 0.606 \\
\hline
\end{tabular}

SEM, Standard error of the mean.

$P$-values $\leq 0.05$ were bolded, while those $>0.05$ but $\leq 0.1$ were underlined.

while numerically higher propionate proportion correlates with the lower $\mathrm{CH}_{4}$ production in the Holstein steers.

We further hypothesized that the above mentioned variation in VFAs and $\mathrm{CH}_{4}$ emissions might be linked with the variation in the rumen microbiota between these two breeds. The two breeds did not differ in the number of observed OTUs, Chao 1 richness estimate, Shannon, and Inverse Simpson diversity indexes, which is in contrast with the report of Paz et al. (2016) who reported significantly higher alpha diversity metrics, including Chaol richness estimate and the number of observed OTUs in Holstein cows than in Jersey lactating cows. This discrepancy might be due to the variation of the microbiota affected by the host genetics and other factors, especially sex (Gonzalez-Recio et al., 2018; Li et al., 2019a) and physiological state (Bainbridge et al., 2016). Among the diverse populations of the rumen microbiota, bacteria are the most abundant domain, accounting for approximately 95\% of the entire rumen prokaryotic microbiota (Zhou et al., 2015). Similarly, the present study found that the rumen microbiota was dominated by bacteria (>99\%) regardless of breed or sampling hour. Bacteroidetes and Firmicutes were the most predominant bacterial phyla in the rumen of both the Holstein and Jersey steers regardless of the sampling hour, and these two phyla had similar relative abundance between the two breeds. This is consistent with the findings of several other studies (Jami and Mizrahi, 2012; Petri et al., 2013; Kim and Yu, 2014; Bharanidharan et al., 2018; Difford et al., 2018; Xue et al., 2018). However, the minor phyla, viz. Fibrobacteres and Candidatus Melainabacteria, varied between the Holstein and the Jersey steers, which might be due to breed effects. Furthermore, the PCoA plot and PCoA ellipses corresponding to the overall rumen microbiota of the two breeds were separated, indicating distinct different rumen microbiota harbored by each breed even fed the same TMR. Consistent with other studies (Bharanidharan et al., 2018; Difford et al., 2018; Xue et al., 2018), Prevotella had the most predominance in both breeds and at both sampling hours. Likewise, Pr. ruminicola was the most abundant Prevotella species, which did not differ between the two breeds. However, their higher abundance at $6 \mathrm{~h}$ after feeding indicates their dominancy increased over time. Sampling hours had little influence on the rumen bacterial 
community, but breeds had a significant influence on it. In this study, the Holstein steers had a significantly higher relative abundance of the genera Ethanoligenens, Succinivibrio, and the species E. harbinense, S. dextrinosolvens, Pr. micans, Pr. copri, Pr. oris, Pr. baroniae, and T. succinifaciens compared to Jersey steers, which indicates that these bacteria fit better to the rumen of the Holstein steers compared to the Jersey steers. Likewise, the Jersey steers had a significantly higher relative abundance of the genera Capnocytophaga, Lachnoclostridium, Barnesiella, Oscillibacter, Galbibacter, and the species Ca. cynodegmi, G. mesophilus, B. intestinihominis, Pr. Shahii, and O. ruminantium than the Holstein steers, indicating their higher activity in the rumen of Jersey steers. Usually, rumen microbial degradation of different feed particles produces VFAs and lactic acids which regulate the ruminal $\mathrm{pH}$. Cattle with high forage diet, that leads to higher $\mathrm{pH}$, had higher relative abundance of phyla Firmicutes and Proteobacteria, genera Fibrobacter, Succinimonas, Polyplastron, Ostracodinium, unclassified Lachnospiraceae, Oribacterium, Pseudobutyrivibrio while higher relative abundance of phylum Bacteroidetes, and genus Prevotella were observed in Cattle received high concentrate diet, which associated with lower $\mathrm{pH}$ (Zhang et al., 2017; Kim et al., 2018; Lee et al., 2019; Zeng et al., 2019; Wang et al., 2020). However, we fed the same TMR which minimizes the influence of diet types on $\mathrm{pH}$ and VFAs in our study. Furthermore, the $\mathrm{pH}$ and VFAs difference observed in the present study might be attributed to the variation of rumen microbiota between breeds through microbial niche modification in the rumen. This is because the ruminal $\mathrm{pH}$ and available metabolites influence initial niche modification (shaping of microbiota composition) by the microbes in the rumen ecosystem after feeding (Shaani et al., 2018). Therefore, rumen microbiota variation between the Holstein and the Jersey steers might be attributed to the influence of breeds, which influences their rumen fermentation and enteric $\mathrm{CH}_{4}$ emission between these two breeds. These results suggested that both the Holstein and the Jersey steers harbor a distinct dominant group of rumen microbes along with common microbes. The rumen microbiota variation between these two breeds was supported by Beecher et al. (2014) and Li et al. (2019a) who reported differences in the rumen microbiome among different breeds.

\section{CONCLUSION}

Though, the Holstein and Jersey steers had similar species richness, Shannon, and inverse Simpson diversity indexes; however, the overall rumen microbiota were different between breeds, and both breeds have a distinct group of dominating rumen microbes. The higher enteric methane emissions was observed in the Jersey steers than that of Holstein steers even they received the same TMR diet. $M$. millerae was more abundant in the Jersey steers while $M$. olleyae in Holstein steers. The results of this study suggest that selective manipulation of rumen microbiome is needed to improve rumen fermentation and reduce $\mathrm{CH}_{4}$ emissions from steers of these breeds. To the best of our knowledge, this is the first comparative study investigating the rumen microbiota and enteric $\mathrm{CH}_{4}$ emissions on Holstein and Jersey steers when fed the same TMR diet.

\section{DATA AVAILABILITY STATEMENT}

The datasets generated for this study can be found in online repositories. The name of the repository (NCBI) and accession number (PRJNA660615) can be found in the following link: https: //www.ncbi.nlm.nih.gov/sra/PRJNA660615.

\section{ETHICS STATEMENT}

The animal study was reviewed and approved by Sunchon National University (SCNU) Institutional Animal Care and Use Committee (IACUC approval number: SCNU-IACUC-2020-06).

\section{AUTHOR CONTRIBUTIONS}

MI, S-HK, and Sa-SL designed and conceptualized the experiments. MI, S-HK, and SR performed feeding and management of steers. MI, S-HK, and A-RS performed the operation of GreenFeed. MI, S-HK, SR, and A-RS performed measurement of body weight and collection of rumen fluids. MI performed laboratory tests and statistical analysis. MI, S-HK, LM, ZY, Su-SL, Y-IC, and Sa-SL were performed data checking. MI wrote the first draft of the manuscript including tables and figures, which was revised by S-HK, LM, ZY, Su-SL, Y-IC, and Sa-SL. All authors contributed to the final manuscript revision, read and approved the final manuscript.

\section{FUNDING}

This research was supported by the Cooperative Research Program for Agriculture Science and Technology Development (Project No. PJ015039032020), Rural Development Administration, South Korea.

\section{SUPPLEMENTARY MATERIAL}

The Supplementary Material for this article can be found online at: https://www.frontiersin.org/articles/10.3389/fmicb.2021. 601061/full\#supplementary-material

Supplementary Table 1 | Relative abundance of rumen microbes of Holstein and Jersey Steers at different taxonomic levels.

Supplementary Table 2 | Bacterial genera each with relative abundance $\geq 0.1 \%$ at least in one breed and at one sampling hour. 


\section{REFERENCES}

Aikman, P. C., Henning, P. H., Humphries, D. J., and Horn, C. H. (2011). Rumen $\mathrm{pH}$ and fermentation characteristics in dairy cows supplemented with Megasphaera elsdenii NCIMB 41125 in early lactation. J. Dairy Sci. 94, 28402849. doi: $10.3168 /$ jds.2010-3783

Aoac. (2005). Official methods of analysis of the Association of Official Analytical Chemists. Gaithersburg: AOAC International.

Appuhamy, J. A. D. R. N., France, J., and Kebreab, E. (2016). Models for predicting enteric methane emissions from dairy cows in north america, europe, and australia and new zealand. Glob. Chang. Biol. 22, 3039-3056. doi: 10.1111/gcb. 13339

Bainbridge, M. L., Cersosimo, L. M., Wright, A. D. G., and Kraft, J. (2016). Rumen bacterial communities shift across a lactation in holstein, jersey and holstein $\times$ jersey dairy cows and correlate to rumen function, bacterial fatty acid composition and production parameters. FEMS Microbiol. Ecol. 92, 1-14. doi: 10.1093/femsec/fiw059

Baldwin, R. L., Wood, W. A., and Emery, R. S. (1963). Conversion of glucoseC14 To propionate by the rumen microbiota. J. Bacteriol. 85, 1346-1349. doi: 10.1128/jb.85.6.1346-1349.1963

Beecher, M., Buckley, F., Waters, S. M., Boland, T. M., Enriquez-Hidalgo, D., Deighton, M. H., et al. (2014). Gastrointestinal tract size, total-tract digestibility, and rumen microflora in different dairy cow genotypes. J. Dairy Sci. 97, 3906-3917. doi: 10.3168/jds.2013-7708

Bharanidharan, R., Arokiyaraj, S., Bae Kim, E., Hyun Lee, C., Won Woo, Y., Na, Y., et al. (2018). Ruminal methane emissions, metabolic, and microbial profile of Holstein steers fed forage and concentrate, separately or as a total mixed ration. PLoS One 13:e0202446. doi: 10.1371/journal.pone.0202446

Bolger, A. M., Lohse, M., and Usadel, B. (2014). Trimmomatic: a flexible trimmer for illumina sequence data. Bioinformatics 30, 2114-2120. doi: 10.1093/ bioinformatics/btu170

Cersosimo, L. M., Bainbridge, M. L., Kraft, J., and Wright, A. D. G. (2016). Influence of periparturient and postpartum diets on rumen methanogen communities in three breeds of primiparous dairy cows. BMC Microbiol. 16:78. doi: 10.1186/s12866-016-0694-7

Chaney, A. L., and Marbach, E. P. (1962). Modified reagents for determination of urea and ammonia. Clin. Chem. 8, 130-132. doi: 10.1093/clinchem/8.2.130

Claassen, S., du Toit, E., Kaba, M., Moodley, C., Zar, H. J., and Nicol, M. P. (2013). A comparison of the efficiency of five different commercial DNA extraction kits for extraction of DNA from faecal samples. J. Microbiol. Methods 94, 103-110. doi: 10.1016/j.mimet.2013.05.008

Danielsson, R., Dicksved, J., Sun, L., Gonda, H., Müller, B., Schnürer, A., et al. (2017). Methane production in dairy cows correlates with rumen methanogenic and bacterial community structure. Front. Microbiol. 8:226. doi: 10.3389/fmicb. 2017.00226

Dieho, K., Dijkstra, J., Schonewille, J. T., and Bannink, A. (2016). Changes in ruminal volatile fatty acid production and absorption rate during the dry period and early lactation as affected by rate of increase of concentrate allowance. J. Dairy Sci. 99, 5370-5384. doi: 10.3168/jds.2015-10819

Difford, G. F., Plichta, D. R., Løvendahl, P., Lassen, J., Noel, S. J., Højberg, O., et al. (2018). Host genetics and the rumen microbiome jointly associate with methane emissions in dairy cows. PLoS Genet. 14:e1007580. doi: 10.1371/journal.pgen. 1007580

Dijkstra, J., Ellis, J. L., Kebreab, E., Strathe, A. B., López, S., France, J., et al. (2012). Ruminal pH regulation and nutritional consequences of low $\mathrm{pH}$. Anim. Feed Sci. Technol. 172, 22-33. doi: 10.1016/j.anifeedsci.2011.12.005

Ellis, J. L., Dijkstra, J., Kebreab, E., Bannink, A., Odongo, N. E., McBride, B. W., et al. (2008). Aspects of rumen microbiology central to mechanistic modelling of methane production in cattle. J. Agric. Sci. 146, 213-233. doi: 10.1017/ S0021859608007752

Flay, H. E., Kuhn-Sherlock, B., Macdonald, K. A., Camara, M., Lopez-Villalobos, N., Donaghy, D. J., et al. (2019). Hot topic: selecting cattle for low residual feed intake did not affect daily methane production but increased methane yield. J. Dairy Sci. 102, 2708-2713. doi: 10.3168/jds.2018-15234

Gonzalez-Recio, O., Zubiria, I., García-Rodríguez, A., Hurtado, A., and Atxaerandio, R. (2018). Short communication: signs of host genetic regulation in the microbiome composition in 2 dairy breeds: holstein and brown swiss. J. Dairy Sci. 101, 2285-2292. doi: 10.3168/jds.2017-13179
Hammond, K. J., Humphries, D. J., Crompton, L. A., Green, C., and Reynolds, C. K. (2015). Methane emissions from cattle: estimates from short-term measurements using a GreenFeed system compared with measurements obtained using respiration chambers or sulphur hexafluoride tracer. Anim. Feed Sci. Technol. 203, 41-52. doi: 10.1016/j.anifeedsci.2015.02.008

Han, S. K., Kim, S. H., and Shin, H. S. (2005). UASB treatment of wastewater with VFA and alcohol generated during hydrogen fermentation of food waste. Process Biochem. 40, 2897-2905. doi: 10.1016/j.procbio.2005.01.005

Henderson, G., Cox, F., Ganesh, S., Jonker, A., Young, W., Janssen, P. H., et al. (2015). Rumen microbial community composition varies with diet and host, but a core microbiome is found across a wide geographical range. Sci. Rep. 5:14567. doi: $10.1038 /$ srep 14567

Hristov, A. N., Oh, J., Giallongo, F., Frederick, T., Weeks, H., Zimmerman, P. R., et al. (2015). The use of an automated system (GreenFeed) to monitor enteric methane and carbon dioxide emissions from ruminant animals. J. Vis. Exp. 2015, 1-8. doi: 10.3791/52904

Islam, M., and Lee, S. (2018). Recent application technologies of rumen microbiome is the key to enhance feed fermentation. J. Life Sci. 28, 1244-1253. doi: 10.5352/JLS.2018.28.10.1244

Islam, M., and Lee, S.-S. (2019). Advanced estimation and mitigation strategies: a cumulative approach to enteric methane abatement from ruminants. J. Anim. Sci. Technol. 61, 122-137. doi: 10.5187/jast.2019.61.3.122

Jami, E., and Mizrahi, I. (2012). Composition and similarity of bovine rumen microbiota across individual animals. PLoS One 7:e33306. doi: 10.1371/journal. pone. 0033306

Johnson, K. A., and Johnson, D. E. (1995). Methane emissions from cattle. J. Anim. Sci. 73, 2483-2492.

Kim, M., and Yu, Z. (2014). Variations in 16S rRNA-based microbiome profiling between pyrosequencing runs and between pyrosequencing facilities. J. Microbiol. 52, 355-365. doi: 10.1007/s12275-014-3443-3

Kim, Y. H., Nagata, R., Ohkubo, A., Ohtani, N., Kushibiki, S., Ichijo, T., et al. (2018). Changes in ruminal and reticular $\mathrm{pH}$ and bacterial communities in holstein cattle fed a high-grain diet. BMC Vet. Res. 14:310. doi: 10.1186/s12917-018$1637-3$

King, E. E., Smith, R. P., St-Pierre, B., and Wright, A. D. G. (2011). Differences in the rumen methanogen populations of lactating jersey and holstein dairy cows under the same diet regimen. Appl. Environ. Microbiol. 77, 5682-5687. doi: 10.1128/AEM.05130-11

Kittelmann, S., Pinares-Patiño, C. S., Seedorf, H., Kirk, M. R., Ganesh, S., McEwan, J. C., et al. (2014). Two different bacterial community types are linked with the low-methane emission trait in sheep. PLoS One 9:0103171. doi: 10.1371/journal. pone. 0103171

Klindworth, A., Pruesse, E., Schweer, T., Peplies, J., Quast, C., Horn, M., et al. (2013). Evaluation of general $16 \mathrm{~S}$ ribosomal RNA gene PCR primers for classical and next-generation sequencing-based diversity studies. Nucleic Acids Res. 41, 1-11. doi: $10.1093 / \mathrm{nar} / \mathrm{gks} 808$

Leahy, S. C., Kelly, W. J., Ronimus, R. S., Wedlock, N., Altermann, E., and Attwood, G. T. (2013). Genome sequencing of rumen bacteria and archaea and its application to methane mitigation strategies. Animal 7, 235-243. doi: $10.1017 / \mathrm{S} 1751731113000700$

Lee, M., Jeong, S., Seo, J., and Seo, S. (2019). Changes in the ruminal fermentation and bacterial community structure by a sudden change to a high-concentrate diet in Korean domestic ruminants. Asian-Australasian J. Anim. Sci. 32, 92-102. doi: 10.5713 /ajas. 18.0262

Li, F., Li, C., Chen, Y., Liu, J., Zhang, C., Irving, B., et al. (2019a). Host genetics influence the rumen microbiota and heritable rumen microbial features associate with feed efficiency in cattle. Microbiome 7, 1-17. doi: 10.1186/s40168019-0699-1

Li, R., Teng, Z., Lang, C., Zhou, H., Zhong, W., Ban, Z., et al. (2019b). Effect of different forage-to-concentrate ratios on ruminal bacterial structure and realtime methane production in sheep. PLoS One 14:0214777. doi: 10.1371/journal. pone. 0214777

Li, W., Fu, L., Niu, B., Wu, S., and Wooley, J. (2012). Ultrafast clustering algorithms for metagenomic sequence analysis. Brief. Bioinform. 13, 656-668. doi: 10.1093/ $\mathrm{bib} / \mathrm{bbs} 035$

Magoč, T., and Salzberg, S. L. (2011). FLASH: fast length adjustment of short reads to improve genome assemblies. Bioinformatics 27, 2957-2963. doi: 10.1093/ bioinformatics/btr507 
McLoughlin, S., Spillane, C., Claffey, N., Smith, P. E., O’Rourke, T., Diskin, M. G., et al. (2020). Rumen microbiome composition is altered in sheep divergent in feed efficiency. Front. Microbiol. 11:1981. doi: 10.3389/fmicb.2020.01981

Moss, A. R., Jouany, J. P., and Newbold, J. (2000). Methane production by ruminants: Its contribution to global warming. Anim. Res. 49, 231-253. doi: 10.1051/animres:2000119

Münger, A., and Kreuzer, M. (2006). Methane emission as determined in contrasting dairy cattle breeds over the reproduction cycle. Int. Congr. Ser. 1293, 119-122. doi: 10.1016/j.ics.2006.01.072

Münger, A., and Kreuzer, M. (2008). Absence of persistent methane emission differences in three breeds of dairy cows. Aust. J. Exp. Agric. 48, 77-82. doi: $10.1071 /$ EA07219

O'Hara, E., Neves, A. L. A., Song, Y., and Guan, L. L. (2020). The role of the gut microbiome in cattle production and health: driver or passenger? Annu. Rev. Anim. Biosci. 8, 199-220. doi: 10.1146/annurev-animal-021419-083952

Olijhoek, D. W., Løvendahl, P., Lassen, J., Hellwing, A. L. F., Höglund, J. K., Weisbjerg, M. R., et al. (2018). Methane production, rumen fermentation, and diet digestibility of Holstein and Jersey dairy cows being divergent in residual feed intake and fed at 2 forage-to-concentrate ratios. J. Dairy Sci. 101, 9926-9940. doi: 10.3168/jds.2017-14278

Paz, H. A., Anderson, C. L., Muller, M. J., Kononoff, P. J., and Fernando, S. C. (2016). Rumen bacterial community composition in holstein and jersey cows is different under same dietary condition and is not affected by sampling method. Front. Microbiol. 7:1206. doi: 10.3389/fmicb.2016.01206

Petri, R. M., Schwaiger, T., Penner, G. B., Beauchemin, K. A., Forster, R. J., McKinnon, J. J., et al. (2013). Characterization of the core rumen microbiome in cattle during transition from forage to concentrate as well as during and after an acidotic challenge. PLoS One 8:0083424. doi: 10.1371/journal.pone.0083424

Prendiville, R., Pierce, K. M., Delaby, L., and Buckley, F. (2011). Animal performance and production efficiencies of holstein-friesian, jersey and jersey $\times$ holstein-friesian cows throughout lactation. Livest. Sci. 138, 25-33. doi: 10 . 1016/j.livsci.2010.11.023

Sas. (2013). Statistical Analysis Systems for windows, version 9.4. Cary, NC, USA: SAS Institute Inc.

Shaani, Y., Zehavi, T., Eyal, S., Miron, J., and Mizrahi, I. (2018). Microbiome niche modification drives diurnal rumen community assembly, overpowering individual variability and diet effects. ISME J. 12, 2446-2457. doi: 10.1038/ s41396-018-0203-0

Spaans, O. K., Macdonald, K. A., Lancaster, J. A. S., Bryant, A. M., and Roche, J. R. (2018). Dairy cow breed interacts with stocking rate in temperate pasture-based dairy production systems. J. Dairy Sci. 101, 4690-4702. doi: 10.3168/jds.201714032

Spor, A., Koren, O., and Ley, R. (2011). Unravelling the effects of the environment and host genotype on the gut microbiome. Nat. Rev. Microbiol. 9, 279-290. doi: $10.1038 /$ nrmicro2540

Tabaru, H., Kadota, E., Yamada, H., and Sasaki, N. T. A. (1988). Determination of volatile fatty acids and lactic acid in bovine plasma and ruminal fluid by high performance liquid chromatography. Jap. J. Vet. Sci. 50, 1124-1126. van Lingen, H. J., Niu, M., Kebreab, E., Valadares Filho, S. C., Rooke, J. A., Duthie, C. A., et al. (2019). Prediction of enteric methane production, yield and intensity of beef cattle using an intercontinental database. Agric. Ecosyst. Environ. 283:106575. doi: 10.1016/j.agee.2019.106575

Van Soest, P. (1973). Collaborative study of acid-detergent fiber and lignin. J. Assoc. Off. Anal. Chem. 56, 781-784.

Van Soest, P. J., Robertson, J. B., and Lewis, B. A. (1991). Methods for dietary fiber, neutral detergent fiber, and nonstarch polysaccharides in relation to animal nutrition. J. Dairy Sci. 74, 3583-3597. doi: 10.3168/jds.S0022-0302(91) 78551-2

Wallace, R. J., Rooke, J. A., Duthie, C. A., Hyslop, J. J., Ross, D. W., McKain, N., et al. (2014). Archaeal abundance in post-mortem ruminal digesta may help predict methane emissions from beef cattle. Sci. Rep. 4, 1-8. doi: 10.1038/srep 05892

Wallace, R. J., Rooke, J. A., McKain, N., Duthie, C. A., Hyslop, J. J., Ross, D. W., et al. (2015). The rumen microbial metagenome associated with high methane production in cattle. BMC Genom. 16:839. doi: 10.1186/s12864-015-2032-0

Wang, L., Zhang, G., Li, Y., and Zhang, Y. (2020). Effects of high forage/concentrate diet on volatile fatty acid production and the microorganisms involved in VFA production in cow rumen. Animals 10:223. doi: 10.3390/ani10020223

Xue, M., Sun, H., Wu, X., Guan, L. L., and Liu, J. (2018). Assessment of rumen microbiota from a large dairy cattle cohort reveals the pan and core bacteriomes contributing to varied phenotypes. Appl. Environ. Microbiol. 84, 1-13. doi: 10.1128/AEM.00970-18

Zeng, H., Guo, C., Sun, D., Seddik, H. E., and Mao, S. (2019). The ruminal microbiome and metabolome alterations associated with diet-induced milk fat depression in dairy cows. Metabolites 9:154. doi: 10.3390/metabo9070154

Zhang, J., Shi, H., Wang, Y., Li, S., Cao, Z., Ji, S., et al. (2017). Effect of dietary forage to concentrate ratios on dynamic profile changes and interactions of ruminal microbiota and metabolites in holstein heifers. Front. Microbiol. 8:2206. doi: 10.3389/fmicb.2017.02206

Zhang, Z., Schwartz, S., Wagner, L., and Miller, W. (2000). A greedy algorithm for aligning DNA sequences. J. Comput. Biol. 7, 203-214. doi: 10.1089/ 10665270050081478

Zhou, M., Chen, Y., and Guan, L. L. (2015). Rumen bacteria. In Rumen Microbiology: From Evolution to Revolution. New. Delhi: Springer.

Conflict of Interest: The authors declare that the research was conducted in the absence of any commercial or financial relationships that could be construed as a potential conflict of interest.

Copyright (c) 2021 Islam, Kim, Ramos, Mamuad, Son, Yu, Lee, Cho and Lee. This is an open-access article distributed under the terms of the Creative Commons Attribution License (CC BY). The use, distribution or reproduction in other forums is permitted, provided the original author(s) and the copyright owner(s) are credited and that the original publication in this journal is cited, in accordance with accepted academic practice. No use, distribution or reproduction is permitted which does not comply with these terms. 